J. Clin. Chem. Clin. Biochem.

Vol. 28, 1990, pp. 169-174

(C) 1990 Walter de Gruyter \& Co.

Berlin - New York

\title{
Adaptation and Evaluation of a Chromogenic Test Procedure for Fibrin Monomers on a Centrifugal Analyzer
}

\author{
By J.W.J. van Wersch \\ Haematological Laboratory, De Wever Hospital Heerlen, The Netherlands
}

(Received September 29/November 24, 1989)

Summary: We evaluated a recently introduced quantitative chromogenic substrate test for the determination of fibrin monomers in plasma (Coa-set FM test). The sample and reagent volume, the reaction time and the composition of the zero standard were modified. In its optimized form the test showed good reproducibility and an acceptable linearity range. Freezing and thawing of the samples does not cause problems. The coefficient of correlation in the comparison of the Coa-set FM test and the Boehringer FM test was $r=0.967$, whereas the conformity was poor. The reference ranges for males and females were not significantly different, resulting in a universal reference range of $8.4-13.2 \mathrm{nmol} / 1$. In conclusion, the Coa-set FM test is, in the modified form, a precise, quick and sensitive method, which can become a valuable tool in the early detection of circulating fibrin monomers.

\section{Introduction}

The clotting process is a complex cascade of enzymatic reactions catalysed by several coagulation factors. Their successive activation leads to the generation of thrombin, which finally induces the formation of cross-linked fibrin (fig. 1). As can be seen from figure 1 , fibrin-monomers are intermediate products in the thrombin-catalysed formation of fibrin. The detection of fibrin monomers produced "in vivo" is only possible "in vitro", when the production rate of the fibrin

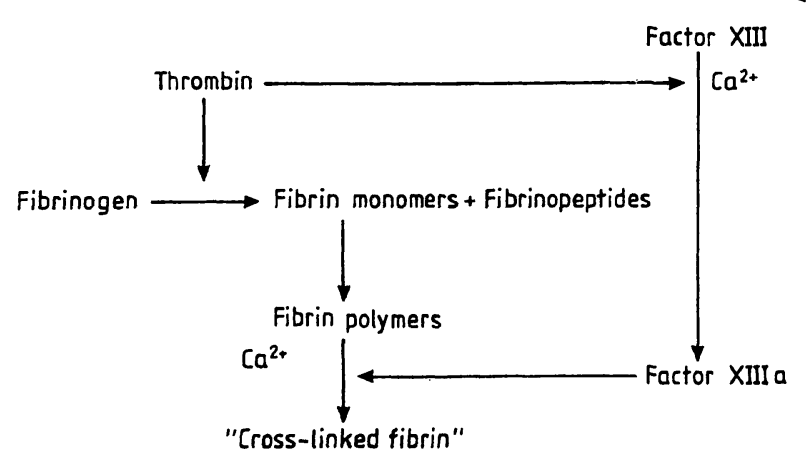

Fig. 1. Relevant part of coagulation cascade monomers surpasses the velocity of the polymerisation reaction. Such conditions can be seen in clinical situations like acute disseminated intravascular coagulation $(1,2)$, active thrombotic processes (3) and malignancies of different origin (4).

For many years fibrin monomers have been detected analytically usually done by the method of Godal (5). The demonstration of fibrin monomers with the Godal test is based upon the ability of the fibrin monomers to form a gel with globular proteins in a $50 \%$ waterethanol solution, which can be assessed macroscopically. Another test was described by Lipinski (6) using protamine sulphate for the detection of soluble fibrin monomer complexes. The so called ethanol-gelation test has several disadvantages:

1. interference by fibrin and fibrinogen degradation products,

2. false positive results in samples with high fibrinogen levels (7),

3. the relative insensitivity of the test, and

4. the inability of the test to be made quantitative. 
An essential change for the better was achieved by the introduction of the fibrin monomer test by Boehringer Mannheim in 1984, based upon the reaction of soluble fibrin monomer complexes with human erythrocytes coated with fibrin monomers. This method originated from Largo et al. in 1976 (8), and it produces semi-quantitative results in form of a titre indicating the last dilution with a positive test result. A new quantitative photometric test (9) has now been introduced by Kabi Vitrum under the name "Coaset fibrin monomer". This is a spectrophotometric determination using a chromogenic substrate according to the reaction scheme in figure 2 . The aim of this study was to evaluate this new product, to compare it with the longer existing FM-test of the Boehringer Mannheim Corporation, and to optimize the test conditions and test use where possible and necessary.

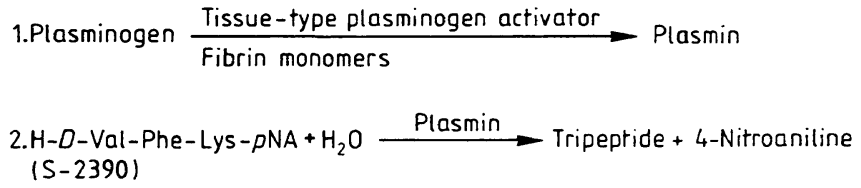

Fig. 2. The reaction scheme

\section{Materials and Methods}

Reagents

The reagents used are listed in table 1 .

\section{Instrument}

For the measurement of the photometric FM-test we used a Cobas Bio centrifugal fast analyzer of Hoffmann La Roche with a pre-incubation device for the proper adjustment of the reagent temperature. For the measurements we programmed the Cobas Bio for a type 6 analysis (two point measurement), which means that the plasminogen as a reagent is simultaneously pipetted with the sample in the cuvette tray. After an incubation time of 10 seconds the mixture of tissue-type plasminogen activator and substrate $\mathrm{S} 2390$ is added as a starting reagent. The instrument settings are given in table 2 .

Tab. 2. Relevant instrument settings of the Cobas Bio

\begin{tabular}{lc}
\hline Temperature $\left({ }^{\circ} \mathrm{C}\right)$ & 25.0 \\
Type of analysis & 6 \\
Wavelength $(\mathrm{nm})$ & 405 \\
Sample volume $(\mu \mathrm{l})$ & 50 \\
Diluent volume $(\mu \mathrm{l})$ & 05 \\
Reagent volume $(\mu \mathrm{l})$ & 50 \\
Incubation time $(\mathrm{s})$ & 10 \\
Start reagent volume $(\mu \mathrm{l})$ & 25 \\
Time of first reading $(\mathrm{s})$ & 0.5 \\
Time interval $(\mathrm{s})$ & 60 \\
Number of readings & 16 \\
Blanking mode & 0 \\
Printout mode & 1
\end{tabular}

\section{Samples}

Venous blood samples were collected by drawing nine volumes of blood into one volume of trisodium citrate $(0.11 \mathrm{~mol} / \mathrm{l})$. After centrifugation for $10 \mathrm{~min}(1600 \mathrm{~g})$ at $25^{\circ} \mathrm{C}$ the plasma was used immediately, or stored at $-70^{\circ} \mathrm{C}$ in plastic tubes until use then thawed for the analysis with tap water for 5 minutes. Normal pool plasma was obtained from 26 subjectively healthy males and 25 females. Samples were prepared by predilution of $50 \mu 1$ test plasma with $2.0 \mathrm{ml}$ tris buffer $\left(20-25^{\circ} \mathrm{C}\right)$.

Tab. 1. List of reagents

\begin{tabular}{|c|c|c|c|}
\hline Test & Reagent & Composition & Distributor \\
\hline \multirow[t]{4}{*}{ Coa-set FM } & $\begin{array}{l}\text { Tris buffer } \\
\text { Lot No. 081989KAD194 S-2390 } \\
\text { Lot No. 071989KAD192 }\end{array}$ & $\begin{array}{l}\text { Tris } 0.063 \mathrm{~mol} / \mathrm{l}, \mathrm{pH} 8.5,0.1 \mathrm{~g} / 1 \text { Tween } 80 \\
\mathrm{H}-D \text {-Val-Phe-Lys- } p \mathrm{NA} \cdot \mathrm{HCl}, 2.9 \mathrm{mmol} / \mathrm{l} \text {, } \\
\text { in } 0.03 \mathrm{~mol} / 1 \text { sodium acetate buffer, } \mathrm{pH} \\
4.2,0.1 \mathrm{~g} / 1 \text { Tween } 80\end{array}$ & Kabi \\
\hline & $\begin{array}{l}\text { Plasminogen } \\
\text { Lot No. } 0519898760051\end{array}$ & Human Glu-Plasminogen $1.5 \mathrm{mg}$ & \\
\hline & $\begin{array}{l}\text { Tissue type plasminogen activator } \\
\text { Lot No. } 1119882887451\end{array}$ & $3.3 \mu \mathrm{g}$ & \\
\hline & $\begin{array}{l}\text { Fibrin monomers } \\
\text { Lot No. } 1119888759951\end{array}$ & $0.5 \mathrm{mg}$ & \\
\hline \multirow[t]{6}{*}{ FM-test (Latex) } & $\begin{array}{l}\text { FM reagent } \\
\text { Lot No. 8B085MAR90 }\end{array}$ & $\begin{array}{l}\text { Human erythrocytes labelled with fibrin } \\
\text { monomers from human fibrinogen }\end{array}$ & $\begin{array}{l}\text { Boehringer } \\
\text { Mannheim }\end{array}$ \\
\hline & $\begin{array}{l}\text { FM control positive } \\
\text { Lot No. } 8 \text { G028JAN90 }\end{array}$ & & \\
\hline & $\begin{array}{l}\text { FM control negative } \\
\text { Lot No. } 8 \text { C } 032 \text { FEB } 90\end{array}$ & & \\
\hline & Aprotinin (Trasylol ${ }^{\circledR}$ ) & $1000000 \mathrm{U} / 1$ & Bayer \\
\hline & $\begin{array}{l}\text { Normal plasma } \\
\text { Lot No. } 8787451\end{array}$ & Human normal plasma & Kabi \\
\hline & $\begin{array}{l}\text { CTS-Control Plasma N } \\
\text { Lot No. A511603A }\end{array}$ & Human normal plasma & Behring \\
\hline
\end{tabular}




\section{Methods}

The tests were carried out according to the instructions of the respective manufacturers. The measurements on the Cobas Bio, however, were performed with one quarter of the original volumes. In each series of determinations 3 standard solutions were used: 0,50 and $200 \mathrm{nmol} / \mathrm{l}$. The preparation of the stock standard $(200 \mathrm{nmol} / \mathrm{l})$ was carried out by reconstituting $10 \mu \mathrm{l}$ fibrin monomer solution with $720 \mu$ f freshly dissolved bovine plasma.

\section{Results}

\section{Reaction curves}

In order to determine the optimal reaction times of the Coa-set FM test we registrated the course of the reaction curves with time (fig. 3). From these plots it can be seen, that the reaction rates became linear after 8 minutes; remarkably, even the zero standard showed a slight absorption increase. Figure 4 shows the results of the investigation of the relationship between the absorption and the fibrin monomer concentration at different reaction times.

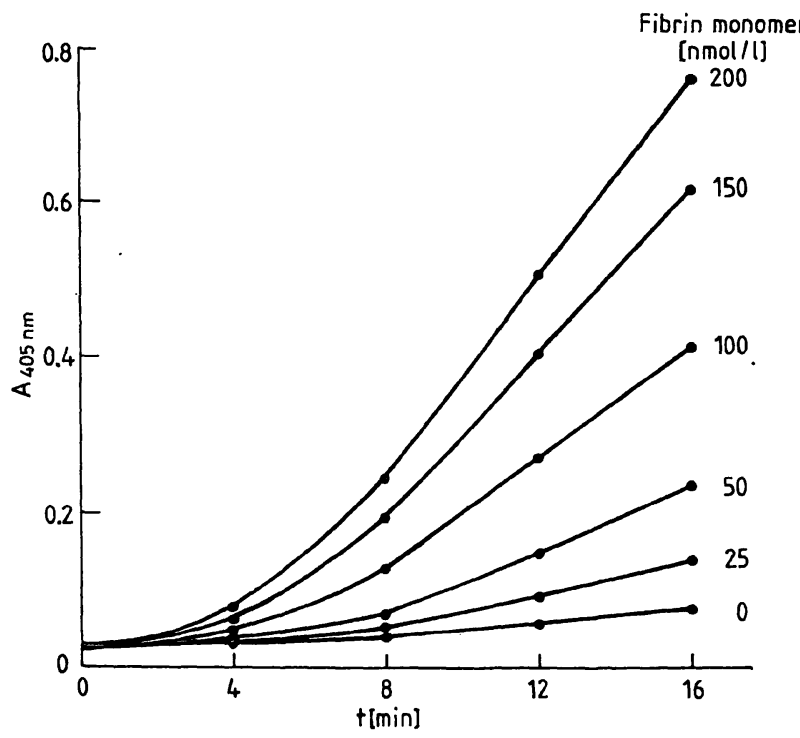

Fig. 3. Absorbance versus time at different fibrin monomer concentrations

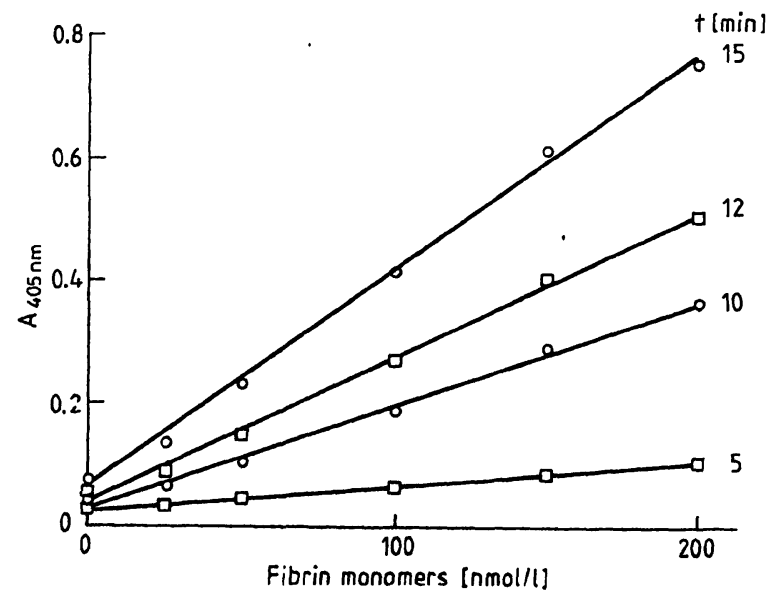

Fig. 4. Absorbance versus fibrin monomers at different reaction times
For all times investigated, there was a satisfactory linear relationship between the absorption and the fibrin monomer concentration used. Only for the shortest reaction time of 5 minutes did the absorption increase seem too slow.

\section{Linearity}

For the investigation of the linearity we tested fibrin monomer concentrations from 0 to $800 \mathrm{nmol} / \mathrm{l}$. The results are given in figure 5. As can be seen, linearity was maintained up to $200 \mathrm{nmol} / \mathrm{l}$.

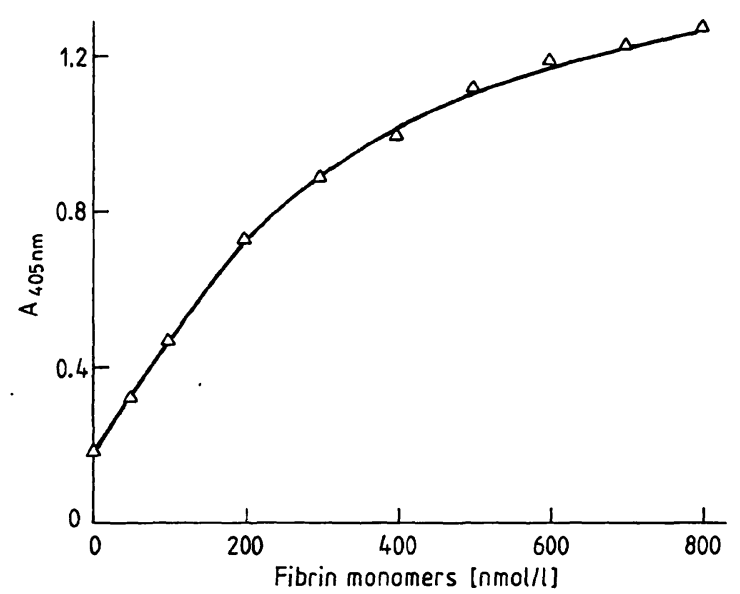

Fig. 5. Linearity of the test

\section{Reproducibility}

For the assessment of reproducibility we determined the intra- and inter-assay variation, each with 10 determinations, and using both the standard and the two pool plasmas (tab. 3). The intra-assay CV ranged, depending on the concentration, from $1.2-4.6 \%$ for the standards and from $1.4-5.4 \%$ for the pool plasmas.

Tab. 3. Intra-assay variation $(n=10)$

\begin{tabular}{lccc}
\hline & \multicolumn{2}{l}{$\begin{array}{l}\text { Concentration of fibrin } \\
\text { monomers (nmol/1) }\end{array}$} & CV (\%) \\
\cline { 2 - 3 } & $\overline{\mathrm{x}}$ & $\mathrm{SD}$ & \\
\hline Standard 1 & 191.4 & 2.2 & 1.2 \\
Standard 2 & 95.2 & 1.2 & 1.2 \\
Standard 3 & 44.8 & 2.1 & 4.6 \\
Pool plasma 1 & 86.7 & 1.2 & 1.4 \\
Pool plasma 2 & 7.4 & 0.4 & 5.4 \\
\hline
\end{tabular}

The inter-assay CV was $3.9-5.9 \%$ for the standards, and $8.0-15.5 \%$ for the pool plasmas (tab. 4). 
Tab. 4. Inter-assay variation $(\mathrm{n}=10)$

\begin{tabular}{lccc}
\hline & \multicolumn{2}{l}{$\begin{array}{l}\text { Concentration of fibrin } \\
\text { monomers (nmol/1) }\end{array}$} & CV (\%) \\
\cline { 2 - 3 } & $\overline{\mathrm{x}}$ & SD & \\
\hline Standard 1 & 193.0 & 7.5 & 3.9 \\
Standard 2 & 105.5 & 3.3 & 3.2 \\
Standard 3 & 53.0 & 3.1 & 5.9 \\
Pool plasma 1 & 96.2 & 7.7 & 8.0 \\
Pool plasma 2 & 9.6 & 1.5 & 15.5 \\
\hline
\end{tabular}

\section{Interference of the matrix}

In the original manufacturer's instruction the standards were dissolved in bovine plasma. The manufacturer, however, recommended fresh frozen plasma as the dissolution medium for the convenience of the customers. Considering this problem, we decided to test four plasmas as dissolution media: bovine plasma, fresh frozen plasma (FFP), lyophilized normal plasma and a deep frozen reference plasma. The results are shown in figure 6 . It can be seen that the variation of the matrix causes clear shifts of the standard calibration lines; especially the zero standard deviates from a linear course in all matrices except bovine plasma. Assuming the existence of a non-specific reaction with the chromogenic substrate, we tried to overcome the slight deviation by adding $10 \mu \mathrm{l}$ of the polyvalent enzyme inhibitor, aprotinin (Trasylol ${ }^{\circledR}$, $100000 \mathrm{U} / 1)$ to $500 \mu \mathrm{l}$ of the zero standard. The results, shown in figure 7 , show that linearity was restored.

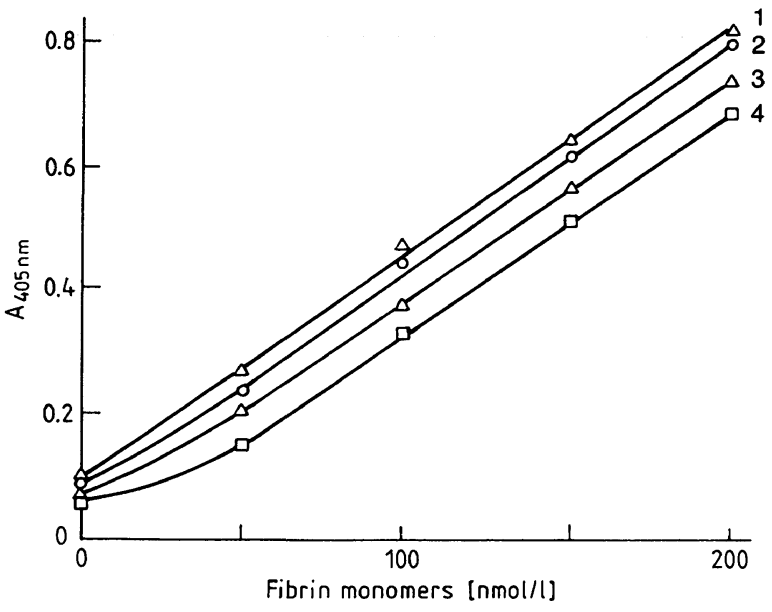

Fig. 6. Interference of the different matrices

$1=$ bovine plasma

$2=$ fresh frozen plasma

3 = lyophilized normal plasma

$4=$ reference $(100 \%$ of normal $)$ plasma

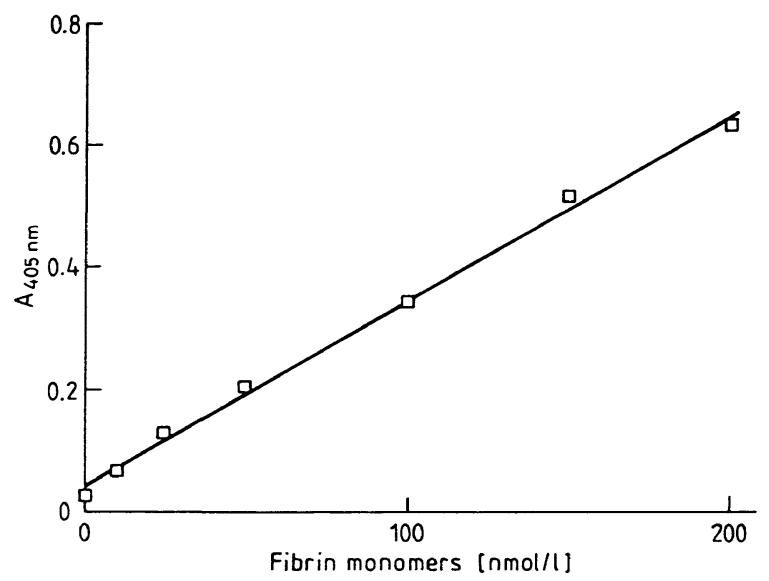

Fig. 7. Calibration curve with aprotinin $\left(\right.$ Trasylol $\left.^{\circledR}\right)$ added to the zero standard

$(r=0.9984 ; y=0.0031 x+0.041)$

The effect of freezing and thawing

Figure 8 shows the effect of freezing and thawing on the recorded fibrin monomer concentrations. We tested five fresh plasma samples after freezing and thawing on five subsequent days. As shown in figure 8 , the CV's are in the range of the inter-assay variations of the different fibrin monomer levels.

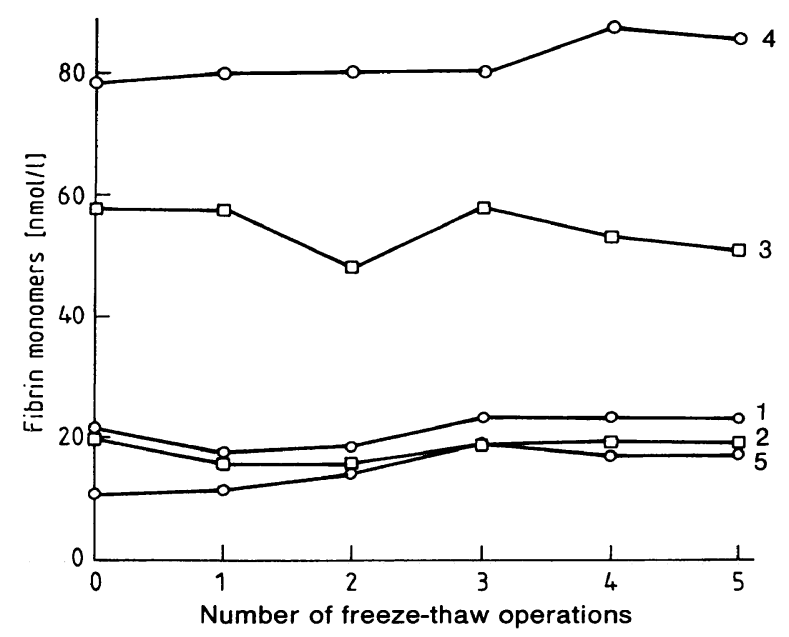

Fig. 8. Effect of freezing and thawing

Sample 1: $\bar{x}=21.4, \mathrm{SD}=2.5, \mathrm{CV}=11.8 \%$;

Sample 2: $\overline{\mathrm{x}}=18.1, \mathrm{SD}=1.9, \mathrm{CV}=10.5 \%$;

Sample 3: $\overline{\mathrm{x}}=54.3, \mathrm{SD}=4.3, \mathrm{CV}=7.9 \%$;

Sample 4: $\overline{\mathrm{x}}=82.4, \mathrm{SD}=3.8, \mathrm{CV}=4.6 \%$;

Sample 5: $\overline{\mathrm{x}}=15.1, \mathrm{SD}=3.4, \mathrm{CV}=22.5 \%$

Comparison of the "Coa-set-FM" test and the "Boehringer FM" test

For the assessment of the correlation between both tests we performed simultaneous determinations on 46 patient plasmas. The titre of the pseudo-latex FM test was plotted against the Coa-set FM test. The coefficient of correlation was 0.967 , with a regression line of $y=6.66 \cdot x-48.0$ (fig. 9). 


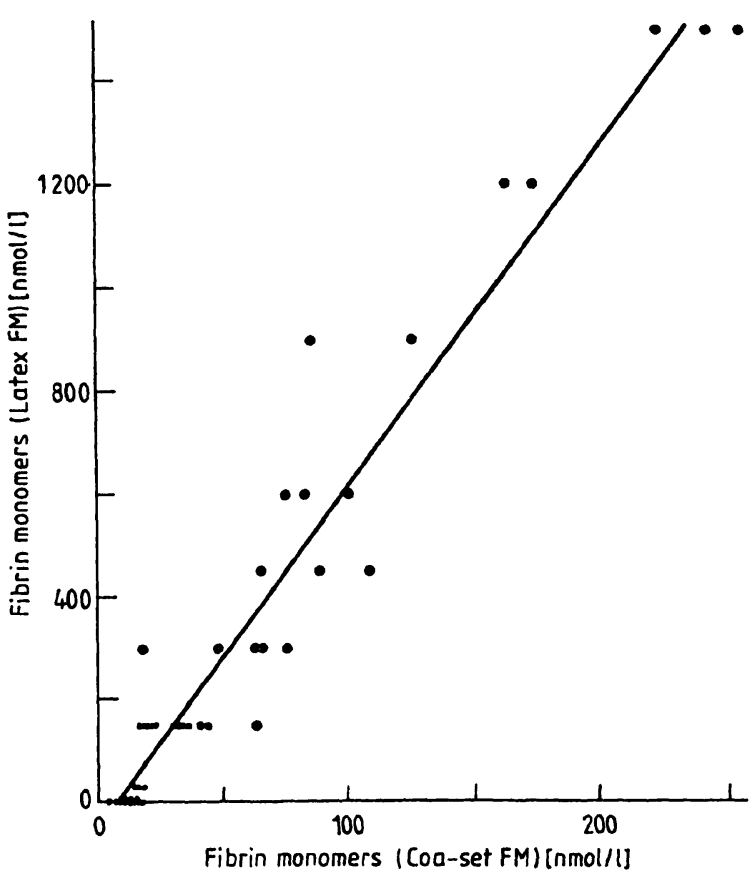

Fig. 9. Correlation between the pseudo-latex FM-test and the Coa-set FM test

$(n=46 ; r=0.9672 ; y=6.66 x-48.0)$

\section{Reference values}

For the determination of the reference values we tested plasmas from 26 males and 25 females. The results are shown in table 5 . Only slight differences were found between the sexes; reference values for males were 8.2-13.9 nmol/1, for females $8.8-12.4$ $\mathrm{nmol} / \mathrm{l}$. The differences were not statistically significant (Student t-test, $\mathrm{p}=0.17$ ) and the values were Gaussian distributed. The reference values can be summarized for both males and females as 8.4-13.2 $\mathrm{nmol} / 1$.

Tab. 5. Reference ranges

\begin{tabular}{lllll}
\hline Gender & Number & Average & $\begin{array}{l}\text { Standard } \\
\text { deviation } \\
\text { nmol/1 }\end{array}$ & $\begin{array}{l}\text { Reference } \\
\text { ranges } \\
\text { nmol/1 }\end{array}$ \\
\hline Male & 26 & 11.06 & 1.41 & $8.23-13.88$ \\
Female & 25 & 10.59 & 0.90 & $8.79-12.40$ \\
All & 51 & 10.8 & 1.2 & $8.4-13.2$ \\
\hline
\end{tabular}

\section{Diagnostic sensitivity}

In figure 10 the Coa-set FM test (cut-off level 13.2 $\mathrm{nmol} / \mathrm{l})$ is compared with the Boehringer FM test (cut-off level for neg/pos decision $10 \mathrm{nmol} / \mathrm{l}$ ). Minor discrepancies between the two methods were found for only 4 out of 46 patient samples. Four concentrations were marginally elevated according to the Coaset FM test, whereas the Boehringer FM test was still negative. All other test samples would have been classified correctly.

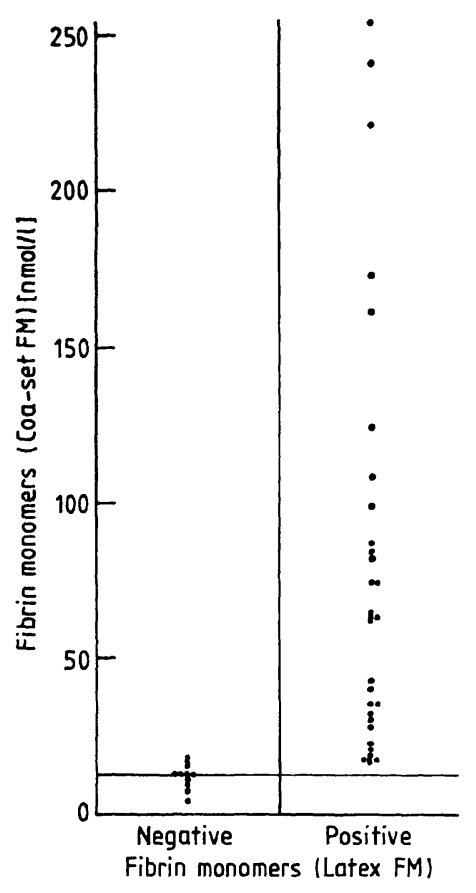

Fig. 10. Relationship of the diagnostic classification of both tests

\section{Discussion}

On the basis of our results we now can reduce the sample volume in the test to one quarter of that recommended by the manufacturer, i.e. to $50 \mu \mathrm{l}$. Moreover the reaction time can be shortened from 20 $\min$ to $10 \mathrm{~min}$ without affecting re reproducibility of the test results. As shown in figures 3 and 6 , there are indications of non-specific reactions in the zero standard. In our opinion this problem can be overcome by adding aprotinin to the zero standard, as shown in figure 7. The reproducibility is good, with intra- and inter-assay coefficients of variation of $1.2-5.4 \%$ and $3.2-15.5 \%$, respectively, depending on the fibrin monomer level. The linearity range is acceptable with a range of $0-200 \mathrm{nmol} / 1$, in relation to the upper reference level of $13.2 \mathrm{nmol} / \mathrm{l}$.

For an economical use of the rather expensive test kit, it is important for sample requests to be analysed in one series after freezing and storing at $-70^{\circ} \mathrm{C}$. Our results show that there is no reason for not adopting this procedure. Our investigation of the matrix interference shows, that bovine plasma can be replaced by fresh frozen plasma as a dissolution medium, if aprotinin is added to the zero standard.

Although the "Coa-set FM test" and the "Boehringer FM test" differ considerably, we obtained a good correlation $(r=0.967)$ between the two methods. It is a pity that the conformity is poor for reasons of using both methods side by side in the laboratory. 
The ranges for males and females $(8.2-13.9 \mathrm{nmol} / \mathrm{l}$ and $8.8-12.4 \mathrm{nmol} / \mathrm{l}$, respectively) were not significantly different, resulting in the range $8.4-13.2$ $\mathrm{nmol} / \mathrm{l}$ for both sexes. These values $(10.8 \pm 1.2$ nmol/l) are nearly the same as those reported by Wiman \& Ranby (9) $(9.2 \pm 1.9 \mathrm{nmol} / \mathrm{l})$. They show that fibrin monomers can be detected in healthy individuals under basic conditions, indicating that fibrinogen is being attacked to a very small extent by thrombin.

Evidence for the presence of slow but continuous conversion of fibrinogen to fibrin in healthy individuals is also reported by Wiman \& Ranby (9) and by Bilezikian, Nossel \& Butler (11). Some marginal notes still should be made about the possible interference of $\alpha_{2}$-antiplasmin and of fibrinogen degradation products (FDP). According to Wiman \& Ranby (9) there is some interference by $\alpha_{2}$-antiplasmin, but it can be ignored, because of the high tissue type plasminogen activator concentration in the test. As to the role of the fibrinogen degradation products we again can

\section{References}

1. Verstraete, M., Vermylen, J. \& Collen, O. (1974) Intravascular coagulation in liver disease. Ann. Rev. Med. 25, 447.

2. Müller-Berghaus, G., Mahn, J., Obst, R. \& Maul, F.-D. (1975) Die Bedeutung löslichen Fibrins (löslicher FibrinKomplexe) für die Verbrauchskoagulopathie. Med. Welt 26, 2163.

3. Hiller, E., Hegemann, F. \& Possinger, K. (1981) Hypercoagulability in acute esophagel variceal bleeding. Thromb. Res. 22, 243-251.

4. Haselager, E. M. \& Vreeken, J. (1981) Clinical significance of circulating fibrin monomers. J. Clin. Pathol. 34, 468472.

5. Godal, H. C. \& Abildgaard, K. (1966) Gelation of soluble fibrin in plasma by ethanol. Scand. J. Haematol. 3, 342.

6. Lipinski, B. \& Worowski, K. (1968) Detection of soluble fibrin monomer complex in blood by means of protamine sulfate test. Thromb. Diath. Haem. 20, 44. refer to Wiman \& Ranby (9), who concluded from their results that in patients with high fibrinogen degradation products levels (about $2000 \mathrm{mg} / \mathrm{l}$ ) only a small influence was observed.

Finally from our results, we can conclude that the diagnostic sensitivity of the "Coa-set FM test" shows good agreement with that of the "Boehringer FM test". There was slight doubt about the correct classification of only 4 out of 46 patient samples. In conclusion, the new "Coa-set FM" test is a precise, quick and sensitive method, which produces reliable quantitative results.

It could therefore become a valuable tool in the early detection of circulating fibrin monomers under different pathological conditions.

\section{Acknowledgement}

The author wishes to thank Ms. Manon Marell for her excellent technical assistance.
7. Gerrits, W. B. J., Prakke, E. M., van der Meer, J. \& Vreeken, J. (1974) Causes of a negative ethanol gelation test in diffuse intravascular coagulation. Thromb. Diath. Haem. 31, 299.

8. Largo, R., Heller, V. \& Straub, P. W. (1976) Detection of soluble intermediates of the fibrinogen-fibrin conversion using erythrocytes coated with fibrin monomers. Blood 47 , 991.

9. Wiman, B. \& Ranby, M. (1986) Determination of soluble fibrin in plasma by a rapid and quantitative spectrophotometric assay. Thromb. Haem. 55, 189-193.

10. Wiman, B. \& Chmielewska, J. (1983) A novel fast inhibitor to tissue plasminogen activator in plasma. Thromb. Res. $31,427-436$.

11. Bilezikian, S. B., Nossel, H. L., Butler, V. P. Jr. \& Canfield, R. E. (1975) Radioimmunoassay of human fibrinopeptide $B$ and kinetics of fibrinopeptide cleavage by different enzymes. J. Clin. Invest. 56, 438-445. 